\title{
Response to Juberg et al.
}

\author{
Axel Mie ${ }^{1,2^{*}}\left(\mathbb{D}\right.$, Christina Rudén ${ }^{3}$ and Philippe Grandjean ${ }^{4,5}$
}

\section{Introduction}

We appreciate the response from the pesticide producer and the test laboratory on our Commentary [1], and we are pleased to be asked for our comments. The response [2] contains some unjustified statements that we wish to call attention to.

\section{Cerebellar dimensions}

Juberg et al. [2] interpret the presence of a statistically significant effect of chlorpyrifos at low and medium dose on cerebellar height of PND 11 pups as a processing artifact due to a prolonged time in fixative, as compared to control and high dose group brains. This new assertion of a delay in processing for certain dose groups is in contradiction to the method descriptions for the PND 11 samples [3, 4].

Furthermore, while shrinking of brain tissue during fixation in formaldehyde solutions is well known, it is not known to selectively affect the cerebellum. However, on PND 11, no other brain regional measures were affected at low and medium dose. Also, no shrinking was observed in the PND 65 female mid-dose cerebellar height, in spite of a documented longer fixation time of these samples compared to control and high dose.

Thus, the lower cerebellar height at all dose levels on PND 11 should be interpreted as treatment-related.

\section{Pup exposure}

For chlorpyrifos, the fetal internal dose (blood concentration) is approximately a factor of 2 below the pregnant dam's internal dose [5]. However, for PND 5 pups, the exposure of the pup via milk is a factor of 50-200 below the dam's exposure $[5,6]$. These data indicate that the nursing pups' exposure falls below intended levels by a very substantial factor. Accordingly, during most of the brain growth spurt, pups were either exposed far below nominal exposures (PND 0-11) or not at all (from PND 12). However, neither the DNT test report [4] nor Juberg et al. [2] acknowledge this limitation. While direct

\footnotetext{
* Correspondence: axel.mie@ki.se

'Department of Clinical Science and Education, Karolinska Institutet,

Södersjukhuset, 11883 Stockholm, Sweden

${ }^{2}$ Centre for Organic Food and Farming (EPOK), Swedish University of

Agricultural Sciences (SLU), Ultuna, Sweden

Full list of author information is available at the end of the article
}

dosing of pups is challenging, technical guidance [7] and specific descriptions for chlorpyrifos [6] exist.

Juberg et al. [2] indicate that early postnatal toxicokinetic data are included in a pilot study report for chlorpyrifos-methyl. These data are not included in the DNT test report, and their impact on the study conclusions are not discussed, despite test guideline requirements [8]. Knowledge regarding the adequacy of postnatal exposure is necessary for an evaluation of the study.

We note that one of the co-authors of the Juberg et al. letter [2] has contributed to the literature on the importance of the offspring's exposure after birth [6]. We therefore find Juberg et al.'s suggestion to begin necessary direct dosing of pups only around PND 10-11 rather surprising and not in accordance with the intention of DNT tests.

\section{Statistical approach}

When we highlighted post-hoc changes in the statistical protocol in our Commentary [1], we referred to the changes that were introduced on 9 April, 1998, i.e., after the draft report had been finalized [4]. Consequences of such post-hoc changes to the statistical protocol are not spelled out [4] but appear e.g. to have changed the conclusion regarding an effect of chlorpyrifos on motor activity at young age. Contrary to what Juberg et al. [2] suggest, the cited paper does not suggest the use of $\alpha=$ 0.02 [9]. We believe that it is inappropriate to use a lower-than-conventional $\alpha$ value in the absence of evidence that adequate statistical power is maintained. When examining in further detail the DNT study, we found a significant effect of chlorpyrifos on motor activity habituation (Dose Group x Block interaction) at high dose that was not reported $[3,4]$.

\section{Positive control}

Juberg et al. [2] speculate that the absence of DNT in the positive control study using lead nitrate might be due to the fact that lead nitrate rather than lead acetate was used. However, no support for this speculation is provided. Juberg et al. [2] suggest a "lack of exposure" as a possible reason for the absence of neurodevelopmental effects. While implausible given the observed effects of 
lead toxicity, including deaths at high dose, this comment is counter to Juberg et al.'s own opinion on the lacking postnatal exposure to chlorpyrifos. Additional positive control data included in the DNT study report, for motor activity only, fail to meet the requirement of age-matching [10]. The test guideline [10] requires that positive control data must "demonstrate the sensitivity of the procedures being used". There is low confidence in any null findings for chlorpyrifos because the DNT study [4] fails on these criteria for all neurodevelopmental endpoints.

\section{Missing data points}

As Juberg et al. [2] point out, it is important that only homologous brain sections are included in morphometrics measurements. A recent test guideline highlights for brain morphometrics that "samples from fewer than 6 animals/ sex/dose level would generally not be considered sufficient for the purposes of this Test Guideline" [11]. In juvenile offspring (PND 21) in the chlorpyrifos-methyl study, numbers of brain sections included for cerebellum height are insufficient by this criterion in three of four groups. However, neither the DNT study report [12] nor Juberg et al. [2] acknowledge this fact, which is only apparent when inspecting the raw data. We also note that individual images for assessment of the homology of sections used for morphometry are, contrary to guideline requirements [8], not included in the test report [12].

\section{Adverse effects in humans}

Juberg et al. [2] claim that "many experts do not agree" with a recent assessment of developmental neurotoxicity in humans and refer to a commentary supported by the American Chemistry Council [13]. A more appropriate reference is the recent review carried out by key scientists who have conducted research on developmental neurotoxicity in children [14]. This review emphasized the clear preponderance of documentation showing a neurotoxic risk from exposures to organophosphate pesticides, such as chlorpyrifos. The assessment of costs within the EU carried out by international colleagues [15] emphasized that the final cost estimates are influenced by parameters such as attributable fractions and exposure levels and that both under- and overestimations are possible. In agreement with this assessment, Dutch researchers recently concluded: "The highest cost of EDC-associated health effects, are found in the group of neurobehavioral diseases, disorders and cognitive conditions. This group of neurobehavioral disorders includes several pervasive disorders that remain during a person's whole lifetime, thereby resulting in substantial costs" [16].
We believe that prevention of such adverse effects is of crucial importance to public health. Reliable and valid safety tests are one necessary prerequisite.

A recent decision from the Court of Justice of the European Union [17] will improve access to all pesticide toxicity studies that EU authorities rely on. That would be a welcome development enabling academic scientists and others to scrutinize these safety tests.

\section{Abbreviations \\ DNT: Developmental neurotoxicity; EDC: Endocrine disrupting compound; EU: European Union; PND: Postnatal day \\ Acknowledgments \\ None. \\ Funding \\ None. PG is supported by the National Institute for Environmental Health Sciences (NIH) (ES027706).}

\section{Availability of data and materials}

The raw data from the pesticide toxicity tests were obtained in accordance with freedom of information legislation.

\section{Authors' contributions \\ AM drafted the reply. All authors contributed to the final version and approved its submission.}

\section{Ethics approval and consent to participate}

N.A

\section{Consent for publication}

All authors approved the final version.

\section{Competing interests}

Authors declare no competing interests. AM and CR provided expert testimony related to pesticide exposure from organic and conventionalfoods in Swedish Patent and Market Courts, case no. PMT11299-16, in 2017, as part of their employment. PG is an editor of this journal but was not involved in the editorial handling of this reply.

\section{Publisher's Note}

Springer Nature remains neutral with regard to jurisdictional claims in published maps and institutional affiliations.

\section{Author details}

${ }^{1}$ Department of Clinical Science and Education, Karolinska Institutet, Södersjukhuset, 11883 Stockholm, Sweden. ${ }^{2}$ Centre for Organic Food and Farming (EPOK), Swedish University of Agricultural Sciences (SLU), Ultuna, Sweden. ${ }^{3}$ Department of Environmental Science and Analytical Chemistry, Stockholm University, Stockholm, Sweden. ${ }^{4}$ Department of Public Health, University of Southern Denmark, Odense, Denmark. ${ }^{5}$ Department of Environmental Health, Harvard T.H. Chan School of Public Health, Boston, USA.

Received: 15 March 2019 Accepted: 19 March 2019

Published online: 03 April 2019

\section{References}

1. Mie A, Ruden C, Grandjean P. Safety of safety evaluation of pesticides: developmental neurotoxicity of chlorpyrifos and chlorpyrifos-methyl. Environ Health. 2018;17(1):77.

2. Juberg D, Hoberman AM, Marty S, Picut CA, Stump DG. Letter to the editor re: commentary in environmental health titled "safety of safety evaluation of pesticides: developmental neurotoxicity of chlorpyrifos and chlorpyrifosmethyl" by Mie et al 2018. Environ Health. 2019. 
3. Maurissen JPJ, Hoberman AM, Garman RH, Hanley TR. Lack of selective developmental neurotoxicity in rat pups from dams treated by gavage with Chlorpyrifos. Toxicol Sci. 2000;57(2):250-63.

4. Anon: Developmental neurotoxicity study of chlorpyrifos administered orally via gavage to $\mathrm{Crl}: \mathrm{CD}^{\circledR} \mathrm{BR}$ VAF/Plus ${ }^{\oplus}$ presumed pregnant rats. 1998.

5. Mattsson JL, Maurissen JP, Nolan RJ, Brzak KA. Lack of differential sensitivity to cholinesterase inhibition in fetuses and neonates compared to dams treated perinatally with chlorpyrifos. Toxicol Sci. 2000;53(2):438-46.

6. Marty MS, Domoradzki JY, Hansen SC, Timchalk C, Bartels MJ, Mattsson JL. The effect of route, vehicle, and divided doses on the pharmacokinetics of chlorpyrifos and its metabolite trichloropyridinol in neonatal SpragueDawley rats. Toxicol Sci. 2007;100(2):360-73.

7. Moser VC, Walls I, Zoetis T. Direct dosing of preweaning rodents in toxicity testing and research: deliberations of an ILSI RSI expert working group. Int J Toxicol. 2005:24(2):87-94.

8. OECD. Test No. 426: developmental neurotoxicity study; 2007

9. Tukey J, Ciminera J, Heyse J. Testing the statistical certainty of a response to increasing doses of a drug. Biometrics. 1985:295-301.

10. US Environmental Protection Agency: Pesticide assessment guidelines: subdivision F, hazard evaluation: human and domestic animals: addendum 10, neurotoxicity, series 81, 82, and 83. Developmental neurotoxicity. 1991

11. OECD: Test no. 443: extended one-generation reproductive toxicity study; $2011+2018$.

12. Anon: A Dietary Developmental Neurotoxicity Study of Chlorpyrifos-Methyl in Rats. 2015.

13. Bond GG, Dietrich DR. Human cost burden of exposure to endocrine disrupting chemicals. A critical review. Arch Toxicol. 2017;91(8):2745-62.

14. Hertz-Picciotto I, Sass JB, Engel S, Bennett DH, Bradman A, Eskenazi B, Lanphear B, Whyatt R. Organophosphate exposures during pregnancy and child neurodevelopment: recommendations for essential policy reforms. PLoS Med. 2018;15(10):e1002671.

15. Bellanger M, Demeneix B, Grandjean P, Zoeller RT, Trasande L. Neurobehavioral deficits, diseases, and associated costs of exposure to endocrine-disrupting chemicals in the European Union. J Clin Endocr Metab. 2015;100(4):1256-66.

16. Rijk I, van Duursen M, van den Berg M. Health cost that may be associated with endocrine disrupting chemicals. An inventory, evaluation and way forward to assess the potential socio-economic impact of EDC-associated health effects in the EU. Utrecht. The Netherlands: Institute for Risk Assessment Sciences (IRAS) Report; 2016. p. 1-86.

17. Court of Justice of the European Union: Judgments ECLI:EU:T:2019:141 + 142. 2019

Ready to submit your research? Choose BMC and benefit from:

- fast, convenient online submission

- thorough peer review by experienced researchers in your field

- rapid publication on acceptance

- support for research data, including large and complex data types

- gold Open Access which fosters wider collaboration and increased citations

- maximum visibility for your research: over $100 \mathrm{M}$ website views per year

At $\mathrm{BMC}$, research is always in progress.

Learn more biomedcentral.com/submissions 